\title{
A narrative systematic review of quantitative and qualitative evidence on the impacts of HIV on women living with HIV and their families in developing countries
}

\section{Nelsensius Klau Fauk ( $\nabla$ nelsen_klau@yahoo.com )}

Institute of Resource Governance and Social Change https://orcid.org/0000-0002-1325-2640

Paul R. Ward

College of Medicine and Public Health, Flinders University

Karen Hawke

Infectious Disease - Aboriginal Health, South Australian Health and Medical Research Institute

Leila Mohamadi

College of Medicine and Public Health, Flinders University

Lillian Mwanri

College of Medicine and Public Health, Flinders University

\section{Research article}

Keywords: WLHIV, HIV impacts, HIV-affected families, developing countries

Posted Date: August 3rd, 2019

DOI: https://doi.org/10.21203/rs.2.11499/v1

License: (c) (i) This work is licensed under a Creative Commons Attribution 4.0 International License.

Read Full License 


\section{Abstract}

Background HIV infections among women cause a range of detrimental impacts on the affected women and their families. This review seeks to understand what impacts are associated with living with HIV in women and their families; and how the identified impacts relate to each other. Methods A systematic review of literature was conducted to identify the impacts of HIV on women and their families in developing countries. We conducted a systematic search of literatures published up to September 2018 in the following databases: Medline, PsycINFO, CINAL, Emcare, Scopus and ProQuest. Articles were included if they were published in English language, with full text available, in developing countries, involving married and non-married women age 15 years and above with HIV and focusing on the impacts of HIV on women and their families. Critical appraisal tools developed by Joana Briggs Institute (JBI) were used to assess methodological quality of the studies and thematic narrative synthesis was used to analyse the findings of the included articles. Results A total of 20 articles were included in the review. The review indicated that HIV infections among women living with HIV (WLHIV) caused numerous negative impacts on WLHIV and their families. They included (i) psychological impacts, (ii) poor physical health and intimate partner violence, (iii) social impacts such as stigma and discrimination, disruption of children's social life and education, family separation and child-parent conflict, and (iv) economic impacts including loss of job and increased family health expenditure leading to poor family economic condition, the sale of family assets, food insecurity and hunger and poverty. Conclusions The findings indicate the need for interventions that address among impacts, psychological, stigma and discrimination and economic consequences of HIV facing WLHIV and their families in developing countries.

\section{Introductions}

Human Immunodeficiency Virus (HIV) infection and the Acquired Immune Deficiency Syndrome (AIDS) have been a worldwide public health problem for over three decades. The 2018 UNAIDS report shows that there were an estimated 36.9 million people living with HIV (PLHIV) worldwide, 1.8 million people newly diagnosed with the infection and 940,000 people died from AIDS-related illnesses in $2017(1,2)$. Globally, of the estimated number of PLHIV, 51\% are women, and of all HIV infected adults about 17.4 million are women. In sub-Saharan Africa where the vast majority of PLHIV (69.6\%) reside, women living with HIV (WLHIV) infection account for $56 \%$ of total cases (2). Women represented $59 \%$ of new HIV infections in 2017 among adults aged 15 and older in the region and an estimated 270,000 women died of AIDSrelated illness in the region in the same year (2). In Asia and the Pacific region, women aged 15 years and older living with HIV represent $30.8 \%$ of the total number of 5.2 million PLHIV, and of these women $54.9 \%$ live in India, $13.7 \%$ in Indonesia, and $11.5 \%$ in Thailand (2).

Women's HIV status is reported to cause detrimental impacts on both women themselves and their families especially those residing in developing countries or resource limited settings. Studies have reported that WLHIV experience various negative psychological challenges including depression, anxiety and worry due to various trepidations arising after HIV diagnosis $(3,4)$. They also experience manifold social impacts such as stigma and discrimination within family, community, workplace and healthcare 
settings $(3,5,6)$. These social consequences are reported to lead to the deterioration of women's wellbeing as a result of both physical and mental or psychological conditions (7-9). The HIV status of women also negatively impacts on their family psychologically, socially and interferes with education of their children (10-12). Further impacts have been reported within HIV-affected families including childmother separation and child-parent conflicts $(11,13)$, and reduced economic power through mechanisms such as loss of jobs, increased health expenditure, food insecurity, hunger and poverty (12-14). Such impacts may lead to a vicious cycle and further health deterioration in WLHIV and their family members due to factors including inability to meet basic needs such as food and health care (15-17).

It is known that most developing countries are similar in several structures such as health care system, social structure, socioeconomic status, environment, belief and understanding, which are different to those of developed countries (18-20). As far as is known, there has not been any published systematic review collating evidence from developing countries on HIV impacts facing WLHIV and their families. This study aimed to explore the literature to improve our understanding of HIV impacts on and the mechanisms through which these impacts influence the life of WLHIV and their families, and how the impacts relate to each other. The need to understand this topic is important because of existing evidence of gendered high burden of disease on WLHIV especially those residing in developing countries compared to men or other key-affected populations (KAPs) $(5,14,21-25)$. It has also been stipulated that HIV impacts on men and other KAPs reported in previous studies might not be applicable to women (26-28). Understanding the impacts of HIV on women and their families may lead to the development of evidencebased interventions that address the needs of WLHIV and their families.

\section{Methods}

\section{Systematic search of literature}

Databases including Medline, PsycINFO, CINAL, Emcare, Scopus and ProQuest were searched to retrieve studies exploring HIV impacts on and the mechanisms through which these impacts influence the life of WLHIV and their families. Inclusion criteria comprised (i) studies with full text available; (ii) studies written in English; (iii) studies conducted in developing countries; (iv) studies involving WLHIV (married \& unmarried); (v) studies aiming at identifying psycho-social, physical, health, economic and educational impacts of HIV on WLHIV and their families (Fig. 1). Even though we wanted to find out articles published from the emergence of the HIV epidemic, the impacts of HIV on women seemed to have emerged in research during the late 1990s. The search of the literature was conducted using several key words in combination (Appendix A) using Boolean operator system including AND and OR. This study was a part of a project exploring HIV risk factors and impacts among WLHIV and their families.

\section{Selection of the studies and methodological quality assessment}


Articles retrieved from the databases were collated and imported into Endnote and duplicates were removed. Titles and abstracts of the retrieved articles were screened by the first author and studies that were not relevant to the topic of the review were removed. Articles that were likely to be relevant were searched for their full texts and reviewed based on the inclusion criteria. The eligible articles were again assessed for methodological quality prior to the inclusion in the review using critical appraisal tools developed by Joana Briggs Institute (JBI) for each study design (29). The methodological quality assessment was conducted by the student (NKF) and one supervisor (LM).

Figure 1: PRISMA Flow diagram of systematic literature search: records identified, removed, screened, and included in the review.

\section{Data extraction and analysis}

As the retrieved articles in this review have different methodological designs, narrative synthesis of quantitative articles was conducted $(30,31)$. Thematic narrative synthesis approach was also used for the analysis of qualitative findings of included articles (32). Table 1 (Description of the included studies in alphabetical order) summarised preliminary synthesis of extracted relevant data including author and year of publication, study location, study design, number of participants, type of analysis, and main themes. Thematic synthesis (32) of text of included articles was conducted, which consisted of a descriptive phase in which authors identified HIV impacts and these were grouped into categories. Two categories including individual level and family level impacts were created. Themes were identified and grouped under each of these categories. Each theme was supported by selected code(s) identified from the qualitative articles (Table 2). This was followed by the second phase which was an explanatory phase where different impacts that emerged from both qualitative and quantitative studies were mapped into a Conceptual Model for the impact of women's HIV status on themselves and their families (Fig. 2).

\section{Results}

\section{Description of the included studies}

A total of 3,316 articles were initially retrieved from five databases and another eight articles were obtained through scrutinising the reference list of the articles. After removing the duplicates, titles and abstracts of 2,284 articles were screened resulting in exclusion of 2,164 articled due several reasons (Fig. 1). Of the remining 120 articles read for full text, only 20 fulfilled the inclusion criteria and were included for the review.

The general characteristics of the included studies are presented in Table 1. Ten studies (11 articles) were conducted in Asia and the Pacific region, six in Africa (4, 6, 23, 33-35), one study (two articles) in Caribbean $(11,12)$, and one study in both Zimbabwe and USA (36). Of the 20 articles, eleven employed face to face qualitative interviews $(4,11,12,14,23,24,34,37-40)$. Nine articles used quantitative methods $(3,5,6,13,25,33,35,36,41)$, of which seven were cross-sectional $(3,5,6,25,33,35,36)$ and 
two were prospective cohort studies $(13,41)$. A total of 2,414 WLHIV participated, of whom 160 and 2,254 respectively were involved in qualitative and quantitative studies. Several studies involved a combination of WLHIV and children $(11,36)$, HIV negative women or women with unknown HIV status (6) and HIV positive men (25), however only the results about WLHIV or the views of WLHIV are included in this review (Table 1). For the study conducted in the Zimbabwe and USA, only the study results about WLHIV in Zimbabwe setting are included in this review (36). The sample sizes or the number of WLHIV who participated in the qualitative and quantitative studies reviewed varied from 1 to 30 and 50 to 633 people, respectively. The participants were recruited using convenient sampling technique or purposive sampling technique or snowball sampling technique. Most of the participants were married women. Eight studies involved married women $(3-6,13,14,39,41)$, the other eight involved a combination of married, widowed and single women $(24,25,33-38)$, while four studies do not report marital status of the participants (11, $12,23,40)$. Participants' age ranged from 15 to 58 years old, while three studies do not report the age of the participants $(11,12,25)$. The qualitative studies mainly used content analysis $(4,23,37,38,40)$ and thematic analysis $(11,12,24,34,39)$ approach for data analysis, except one study which employed a combination of thematic analysis, analysis of episode and identification of paradigm cases (14). The majority of the quantitative studies used one or a combination of bivariate and multivariate linear or logistic regression models for data analysis $(3,5,6,33,35,36,41)$.

Table 1: Description of the included studies in alphabetical order

\section{Impacts of HIV on WLHIV and their family}

Four main themes identified in this review including (i) psychological impacts, (ii) physical health impacts and intimate partner violence, (iii) social impacts, and (iv) economic impacts are elaborated below. The mechanisms through which these impacts influence the life of WLHIV and their families, and how the impacts relate to each other are also described.

\section{Psychological impacts}

Psychological challenges such as depression, worry and anxiety are the most common HIV impacts experienced by WLHIV $(3,42)$. These often emanate from innumerable trepidations that WLHIV face after HIV diagnosis. Advanced stage of HIV infection, poor physical health condition, fear of breach of confidentiality of HIV status and the feelings that HIV status would be a shameful experience to the family are factors associated with the psychological impacts facing them $(3,41)$, just to mention a few. Fear of transmitting HIV infection to unborn babies, concerns about growth and future of their children in case of their untimely death, inability and lack of resources to take care of their children, were also reported to cause psychological distress for $\operatorname{WLHIV}(13,23,34,41,43)$. Other factors including lack of social support, social rejection, internalised stigma $(33,35)$ and a reduction of family income and poor economic conditions $(24,41)$ were reported to cause depression and worry among WLHIV. Women's sociodemographic characteristics including lower education attainment, being primary caretaker for 
children, no longer in a relationship with partners and/or (husbands died, poor health, single marital status), unintended pregnancy, family misfortunes, chronic disease, detection of viral load, and poor CD4 pT cell count $(33,35,41)$ were additional predictors of poor psychological functioning. Moreover, women's HIV status was reported to negatively impact the psychological state of other family members especially their children, which was reflected in children feeling upset, hurt, sad and worried due to their mother health condition $(11,12)$.

\section{Physical health impact and intimate partner violence (IPV)}

HIV infection also has a significant impact on physical health, including that WLHIV experience reduced physical strength, difficult sleeping, dizziness and exhaustion after HIV diagnosis $(12,14,34)$. Such poor physical health can jeopardize their day to day functioning including looking after their children, and their ability to work and provide for their children $(12,14)$. Besides, being diagnosed with HIV infection can also lead to physical violence and maltreatment by intimate partners such as husbands or spouses (intimate partner violence) $(14,23)$.

\section{Social impacts}

Stigma and discrimination against WLHIV. WLHIV experience both HIV-related self-stigma and enacted or external stigma manifested in various kinds of discriminative attitudes and behaviours $(3,5)$. Paranoia about people's reactions to their HIV status and believing that people are talking about them are the instances of negative self-stigma that WLHIV have about themselves after HIV diagnosis (42). Fear of HIV status being recognised and spread out by other people and fear of rejection and negative reactions from family members are other types of self-stigma experienced by WLHIV, which often leads to women isolating themselves or hiding their HIV status from family members $(4,13,37)$. Other factors associated with perceived stigma among WLHIV include low perceived availability of instrumental and emotional support, the fear that their children would be stigmatised, discriminated against and disallowed in schooling $(24,33)$. Sociodemographic factors including being older women, having low education, husbands having other wives, and perceived community discrimination against people with HIV are also associated with perceived stigma among WLHIV (6).

WLHIV are also reported to face various external stigma and discrimination within their own family, community, workplace and healthcare settings $(4,5,23,25,34,38,39)$. Close family members such as husbands and in-laws, parents and siblings tend to stigmatise and discriminate against them. Being blamed, verbally insulted, avoided and rejected by in-laws or the family of their late husbands are some instances of HIV-related stigma and discrimination that faced married WLHIV $(5,38)$. The experience of being chased away or expelled from their homes by parents in-law is also another form of HIV-related discrimination against married WLHIV within family $(4,25,38,39)$. A study by Halli et al. (5) reported several sociodemographic factors associated with stigma and discrimination against WLHIV by husbands and husbands' family members. These include occupation of the husbands, older age of the 
husband, higher age gap between spouses and lower household economic status. Stigma and discrimination against WLHIV have also been reported to have come from their own parents and siblings $(5,13,25,34,37,38)$. Being asked to leave home by their own parents $(34,38)$, separation of their personal items from those of other family members and exclusion of WLHIV from usual family activities including cooking and sharing utensils or eating implements and rooms $(5,13,25,37)$ are some forms of discriminative behaviours against WLHIV within families.

HIV-related stigma and discrimination against WLHIV also occur within communities where they live (4-6, $12,13,23,25,34,37-40)$. Social isolation such as being rejected and neglected, and burning of the possessions of WLHIV by their friends, and being expelled by neighbours from rented house where they live are HIV-related social stigma and discrimination against WLHIV within communities $(4,6,13,34,37)$. Neighbours and relatives refusing to share food and drink with them and being left by friends and relatives are additional forms of rejection and neglect experienced by WLHIV as the consequence of their HIV status $(13,37)$. Physically assaulted, being labelled or verbally abused with discriminative words such as "HIV carriers" or "she is (HIV) positive", insulted and harassed by other community members are also experiences of HIV-related stigma and discrimination facing $\operatorname{WLHIV}(25,38,39)$. Being excluded from usual activities or social functions, refused to enter or removed from public establishment and the change of their place of residence from one community to another voluntarily or by force are also experienced by women due to their HIV status (25).

Stigma and discrimination against WLHIV also occur in healthcare settings, reflected in discriminative treatments or behaviours of healthcare professionals towards WLHIV. Criticism, blaming, shouting at or throwing health record on patients' face, rejection and unnecessary referrals, and neglection or leaving patients untreated once patients' HIV status is known to them are some forms of discriminative behaviour of healthcare professionals against $\operatorname{WLHIV}(6,23,25,39,40)$. Being coerced to undergo HIV testing, and abortion and sterilisation after HIV diagnosis, and loss of private health insurance due to being diagnosed with HIV are other instances of healthcare-related discrimination against WLHIV (25). As the consequence, WLHIV often hide their HIV status and go untreated $(39,40)$, which may lead to advanced stage of HIV infection. Stigma and discrimination against WLHIV also occur in the workplace setting manifested in loss of prospects for promotion and change in job descriptions. Business customers have also been reported to fear using services provided by WLHIV's services $(25,34)$, which may be consequential to WLHIV.

Stigma and discrimination against HIV-affected family members. HIV-related stigma and discrimination such as rejection and social exclusion by friends, relatives or other community members are also experienced by HIV-affected family members of WLHIV $(11,12,24,37,39)$. Children of WLHIV often face stigma and discrimination due to their mothers' HIV status. They are rejected, teased or mocked, cursed, abused and isolated by their friends and significant others. For example, they are told "your mother has HIV", called "little HIVer" by friends $(11,12)$ and placed at a separate desk by teachers, while other children are told not to play with them at school and within community where their live $(37,43)$. 
Impacts of mothers' HIV status on children's social life and education. Women's HIV status poses negative impacts on various aspects of their children's life. For example, it prevents children from activities such as socializing with friends, being involved in extracurricular school and peer activities, and doing school homework as they take additional responsibility for household chores on behalf of their sick mothers (13). Positive HIV status of mothers also influences children's education due to factors such as children missing school once their mothers are unwell, children worrying and developing poor focus on studying which lead to poor education performance or achievement (12). Children who have unwell mothers due to HIV have poor school attendance due to mothers failing to provide food for them to eat to sustain attending school (12). Additionally, in some instances, children of mother who are HIV positive are denied school admissions and kicked out from school due to pressure or complaints from the parents of other students (25). Maternal positive HIV status has also been reported to be associated with poor family economic condition, with multitudes of consequences including inability to pay for school fees (12).

Family separation and child-parent conflicts. A situation where children are voluntarily taken away and separated from their mothers by in-laws due to the HIV status of the mothers is another social impact of HIV on HIV-affected families $(13,25,39)$. Mothers with HIV are reported to also voluntarily give away their children to live with their siblings or sister in-law or brother in-law's family once they are terminally ill or hospitalised (14). The main reasons for such separation are poor physical health and economic conditions of the mothers which make them unable to take care of and raised their children $(12,14)$. Husband-wife separation or abandonment by husband is another negative impact of HIV on the families of WLHIV $(12,25,34)$, which may render difficulties in women taking care of themselves and their children (34). HIV status of mothers also brings conflict to parent-child relationship (36). For example, children may intend to hurt their father due to anger and blame when perceived their father to be the source of infection to their mothers(11).

\section{Economic impacts}

HIV infection is reported to adversely influence economic aspect of WLHIV through several mechanisms. In this review, two studies with WLHIV reported that women lost their jobs or potential work due to their HIV status $(25,34)$. Women's poor physical strength preventing their involvement in work is another mechanism through which the infection affects their economic life $(14,34)$. Women's HIV status is also reported to influence their willingness to apply for jobs that require HIV test for applicants (13). Study by Paxton and colleagues also reported that WLHIV lost financial support from their spouse and other family members due to their HIV status (25).

The economic impact of HIV on WLHIV has negative influence on their family economic condition (12-14, 34,39 ), including the reduction of family income due loss of jobs or unemployment and inability of women to work (13). Similarly, it is reported that some clients or customers stop using the family business services after learning about the HIV status of women in the family (39), resulting in the 
downfall of the family business. Increased family healthcare expenses $(14,34)$, which may lead to selling family properties including land and houses to cover healthcare expense and to survive $(12,14)$ are additional economic impact of women's poor health due to HIV. When families sell main sources of their livelihood such as the land and other essential resources to recuperate, such circumstance had been reported to lead to food insecurity, hunger, poverty $(12,14)$, and endless cycle of deprivation within the family of WLHIV. Table 2 below summarises the qualitative evidence of the impacts of HIV on WLHIV and their families.

Table 2: Qualitative evidence of the impacts of HIV on WLHIV and their families

\section{Discussion}

\section{Summary of findings}

The primary objective of this systematic literature review was to understand the impacts of HIV on WLHIV and their families in developing countries. A total of 20 studies comprising nine quantitative and 11 qualitative studies were included in this review. Of nine quantitative studies reviewed, six studies focused on exploring the impacts of HIV on WLHIV $(3,5,6,33,35,41)$, two covered both HIV impacts on WLHIV and their family $(13,25)$ and one explored HIV impacts on family only $(36)$. HIV impacts on WLHIV, which are presented in these quantitative studies include psychological challenges and the associated factors $(3,13,33,35,41)$ and stigma and discrimination against WLHIV within family, community, workplace and healthcare settings $(5,6,13,25,33,35)$. HIV impacts on family of WLHIV reported in three studies include family separation, child-parent conflict, impacts on children's social life and education and on family economic condition $(13,25,36)$.

Of the 11 qualitative studies reviewed, six explored the impacts of HIV on both the women and their families $(12,14,24,34,37,39)$, four studies focused on HIV impacts on WLHIV $(4,23,38,40)$ and one investigated the impacts on families of WLHIV (11). The majority of these qualitative studies explored stigma and discrimination facing $\operatorname{WLHIV}(4,12,14,23,24,34,37-40)$ and their family members especially children within family, community, healthcare and school settings $(11,12,24,37,39)$. A few studies explained the psychological impacts of HIV infection on $\operatorname{WLHIV}(4,23,24,34)$ and their children (11). Topics such as economic impacts of HIV on WLHIV (34) and their families $(12,14,34,39)$, physical health impacts of HIV on WLHIV $(12,14,34)$, intimate partner violence against WLHIV $(14,23)$, family separation $(12,14)$ and HIV impacts on children's education were also presented in these studies.

\section{An explanatory conceptual model for the impacts of HIV on WLHIV and their families}

These findings show two main categories of HIV impacts, that are, the impacts on WLHIV at individual level and on their families. Drawing on the findings from the studies reviewed and conceptual framework 
for the socio-economic impacts of the HIV/AIDS epidemic on households (44), an explanatory Conceptual Model for HIV impacts on WLHIV and their families was developed to visually represent the connection between the emerging themes (see Fig. 2).

Figure 2: Conceptual Model for HIV impacts on WLHIV and their families

The Model suggests that women's HIV status causes a range of negative impacts on both women themselves and their families. At the individual level: firstly, it causes psychological challenges for women such as depression, worry and anxiety. Such psychological challenges can be triggered by miscellaneous concerns the women have after being diagnosed with HIV. For example, concerns about their health condition, concealment of their HIV status, stigma and discrimination, family becomes ashamed due to their HIV status, and the health condition and the future of their children. Secondly, it leads to poor physical strength which influences women's ability to do physical activities, work and take care of themselves and their children. It can also lead to physical violence or abuse against them by their husband, partner or spouse due to unacceptance of their HIV status. Thirdly, HIV infection causes stigma and discrimination against WLHIV, reflected in various kinds negative behaviours such as rejection, insult, avoidance, isolation, neglection, being chased away from home and verbally abused. Stigma and discrimination may occur within family, community, healthcare and workplace settings by family members, community members, healthcare professionals, and employers or colleagues or customers. Some of these impacts, including rejection by family, abuse by husband and in-laws, selective maltreatment in pregnancy by healthcare professionals especially when HIV status is known, HIV testing by coercion, sterilisation and abortion have not been reported as HIV impacts on men and other KAPs (2628). Rejection and abuse against WLHIV by husbands and in-laws, for example, seem to be the consequences of the patriarchal system or sociocultural norms and values prevailing within societies and communities in many developing countries, that promote male or husbands' domination over women or wives' submission to husbands or male partners (45-49). Being infected with HIV also causes negative self-stigma among WLHIV, such as paranoia about people's negative reactions to their HIV status, fear of HIV status being recognised and spread out by other people and fear of rejection, and self-isolation. Such stigma and discrimination can further worsen psychological condition of WLHIV. Fourthly, it also leads to economic or financial hardship as WLHIV lose their jobs or cannot apply for jobs and lose opportunity to get job promotion due to their HIV status.

Women's HIV status also brings adverse impacts on their families. Firstly, in line with the constructs of the framework for the socio-economic impacts of HIV/AIDS on households and other studies' findings (44, 50-53), this Model suggests that women's HIV status can lead to reduced family income due to loss of jobs of infected family members (WLHIV) or loss of family business and increased family health expenditure leading to economic or financial difficulties within the affected families. Such economic condition can cause several further impacts such as food insecurity, declined children's food intake, hunger, sale of family properties such as lands and houses, and poverty within HIV-affected families. This chain of economic impacts can deteriorate women's psychological condition further and worsen their physical health condition. Several other studies have reported that poor economic condition or 
poverty within HIV-affected families may also lead to withdrawal of children from school due to unaffordability of parents to pay for school fees or buy supplies $(44,51,54,55)$. Secondly, women's HIV status can lead to family separation such as child-mother and husband-wife separation. Inability of mothers to take care of their children due to the sickness and unacceptability of women's HIV status by their husband or spouse are the instances of underlying reasons for family separations. Women's HIV status can cause children-parents conflict due to fathers being accused of transmitting HIV infection to their mother. Thirdly, it causes stigma and discrimination against the women's family members especially their children. Social rejection, avoidance, abuse, curse, and being labelled with discriminative words are the examples of stigma and discrimination facing children of HIV-affected family. Fourthly, it also influences psychological state, social life and education of their children. Feeling upset, hurt and worried about their mother's condition are the instances of psychological impacts of mother's HIV status on their children. Children miss out socialisation with friends and are less involved in extra-school activities due to being responsible for household chores and taking care of their sick mother are some of the impacts of women's HIV on their children's social life. Such HIV impacts on social life of children seem less likely to occur within HIV-affected families where mothers are not infected as they traditionally have primary household, child and husband responsibilities $(21,45,56)$. Denied from school admission or kicked from school due to mother's HIV status, less school attendance due to mother being sick and low academic performance are the educational impacts of mother's HIV status of their children. Other studies have also reported that involvement of children of HIV-affected families in household chores or farms or income generating activities may result in school dropout $(44,51,57)$.

\section{Implications for future practices or interventions}

This systematic review synthesises evidence on the impacts of women's HIV status on women and their families. Evidence presented in this review show that there are several aspects that need to be addressed in future responses or interventions to HIV impacts facing WLHIV and their families.

\section{Addressing psychological challenges on WLHIV}

This review suggests that women are subjected to a range of psychological challenges such as depression, worry and anxiety due to numerous concerns that come into mind following their HIV diagnosis. These psychological challenges may further lead to the deterioration of their physical health condition and contribute to the progression of HIV infection. Thus, responses to HIV impacts need to address the psychological impacts facing WLHIV. Such psychological impacts can be addressed through HIV-related education and counselling to help WLHIV manage them and reduce the occurrence (58). Counselling can also be a useful strategy through which WLHIV are linked to supports for adaptation with their status as persons living with HIV (59). For example, linking them to become involved in HIV/AIDS peer support groups that provide them with opportunity to share information and experience, and gain support from other PLHIV can help them to cope with various HIV-related psychological challenges facing 
them. Counselling is also reported to increase patients' adherence to ART which can improve their physical health condition (60). Likewise, family counselling will be of great benefit for WLHIV psychologically as it can help increase family understanding and acceptance, reduce stigma and improve treatment of WLHIV (61-63).

\section{Addressing stigma and discrimination against WLHIV and their children}

This systematic review shows that WLHIV experience of stigma and discrimination within family, community, healthcare and workplace settings. Similarly, children of WLHIV are stigmatised and discriminated by their friends and teachers at school and by other community members. Discrimination can lead to other impacts including depression and denial of women's access to healthcare services, and children being denied from school admission and expelled from school. Thus, this review suggests that stigma and discrimination against WLHIV and their children should be addressed at community and societal level covering family, community, school, healthcare and workplace settings as the sources of stigma and discrimination. HIV/AIDS education for family and community members, teachers, students and healthcare professionals to raise their awareness of HIV/AIDS and acceptance of PLHIV can be an effective strategy to address stigma and discrimination against WLHIV and their children and gain social supports from them $(61,64)$. Health systems interventions that seek to build positive self-perceptions and confidentiality of WLHIV can also be useful strategy to address stigma and discrimination against WLHIV (65). These may also lead to reducing internalised stigma which often comes from negative selfperceptions and over worried and fear of other people's reactions.

\section{Addressing economic impacts of HIV on WLHIV and their families}

Women's HIV status causes economic hardship on women and their families through various mechanisms such as loss of jobs and increase family health expenditure, which may lead to food insecurity, hunger, sale of family assets and poverty within their families. Such economic impacts can be addressed through policy interventions that promote free access to HIV/AIDS-related healthcare services for PLHIV and opportunities for PLHIV to engage in workforce $(66,67)$. In addition, HIV/AIDS interventions that consider the larger context of women's lives, including their responsibility for household and caregiving role within family are also recommended.

\section{Implication for future studies}

None of these studies reviewed focused on psychological impacts of HIV on HIV-affected family members of WLHIV even though some studies reported scant information related to psychological impacts on children. Similarly, none of the studies reviewed have looked at stigma and discrimination against family members other than the children. None of the included studies explored the impacts of 
women's HIV status on the work or job of their family members even though a study provided limited information about its impact on family business. Finally, none of these studies looked at the roles cultural and religious values, norms and thoughts play in mitigating or exacerbating the impacts of HIV on WLHIV and their families in developing countries. Future studies that address these aspects are recommended.

\section{Limitation of the study}

This review only included studies conducted in developing countries. Thus, evidence on the lived experiences of WLHIV in developed countries about the impacts of HIV on themselves and their families was not covered in this review. To build a comprehensive picture of HIV impacts facing WLHIV and their families, future literature reviews that include studies on this topic conducted in developed countries are recommended. Another limitation is that this review included English peer review literature only, thus may have missed studies on this topic, which are reported in other languages.

\section{Conclusion}

HIV infections cause a range of negative consequences on WLHIV and their families. The Conceptual Model for HIV impacts at individual and family level presents evidence on various impacts of HIV on WLHIV and their families and how the impacts relate to each other. This Model can help in designing interventions that address psychological, financial, social and physical needs of WLHIV and their family to ensure that they have the best quality of life, and that support them to cope with the HIV impacts facing them and their families.

\section{List Of Abbreviations}

AIDS : Acquired Immune Deficiency Syndrome

UNAIDS : The Joint United Nation Programme on HIV and AIDS

ART : Antiretroviral Therapy

HIV : Human Immunodeficiency Virus

JBI : Joana Briggs Institute

KAP : Key-Affected Population

PLHIV : People Living with HIV

WLHIV : Women Living with HIV

\section{Declarations}


Ethics approval and consent to participate: Not applicable

Consent for publication : Not applicable

Availability of data and material: All data generated or analysed during this study are included in this published article

Competing interests : Authors declared no conflict of interests

Funding: This study did not receive funding from any institutions

Acknowledgements : Not applicable

\section{References}

1. UNAIDS. Global HIV \& AIDS Statistics - 2018 Fact Sheet. Geneva, Switzerland: Joint United Nations Programme on HIV/AIDS. Available at: http://www.unaids.org/en/resources/fact-sheet; 2018.

2. UNAIDS. UNAIDS data Geneva, Switzerland: Joint United Nations Programme on HIV/AIDS. Available at: http://www.unaids.org/sites/default/files/media_asset/unaids-data-2018_en.pdf; 2018.

3. Qin S, Tan Y, Lu B, Cheng Y, Nong Y. Survey and analysis for impact factors of psychological distress in HIV-infected pregnant women who continue pregnancy. The journal of maternal-fetal \& neonatal medicine : the official journal of the European Association of Perinatal Medicine, the Federation of Asia and Oceania Perinatal Societies, the International Society of Perinatal Obstet. 2018:1-8.

4. Ruffell S. Stigma kills! The psychological effects of emotional abuse and discrimination towards a patient with HIV in Uganda. BMJ Case Reports. 2017;1(1):1-8.

5. Halli SS, Khan CGH, Moses S, Blanchard J, Washington R, Shah I, et al. Family and community level stigma and discrimination among women living with HIV/AIDS in a high HIV prevalence district of India. Journal of HIVAIDS \& Social Services. 2017;16(1):4-19.

6. Cuca YP, Onono M, Bukusi E, Turan JM. Factors associated with pregnant women's anticipations and experiences of HIV-related stigma in rural Kenya. AIDS Care. 2012;24(9):1173-80.

7. Catalan J, Beevor A, Cassidy L, Burgess AP, Meadows J. Women and HIV infection: investigation of its psychosocial consequences. Journal of Psychosomatic Research. 1996;41(1):39-47.

8. Pergami A, Gala C, Durbano F, Zanello D, Burgess A, Riccio M, et al. The psychological impact of HIV infection in women: controlled investigation. J Psychosom Res. 1993;37:687-96.

9. Catalan J, Bradley M, Gallwey J, Hawton K. Sexual dysfunction and psychiatric morbidity in patients attending a clinic for sexually transmitted diseases. Br J Psychiatry. 1981;138:292-6. 
10. Murphy DA, Austin EL, Greenwell L. Correlates of HIV-Related Stigma Among HIV-Positive Mothers and Their Uninfected Adolescent Children. Women \& Health. 2007;44(3):19-42.

11. Conserve D, Eustache E, Oswald C, Louis E, King G, Scanlan F, et al. Disclosure and Impact of Maternal $\mathrm{HIV}+$ Serostatus on Mothers and Children in Rural Haiti. Maternal \& Child Health Journal. 2014;18(10):2309-15.

12. Conserve DF, Eustache E, Oswald CM, Louis E, Scanlan F, Mukherjee JS, et al. Maternal HIV illness and its impact on children's well-being and development in Haiti. Journal of Child and Family Studies. 2015;24(9):2779-85.

13. Manopaiboon C, Shaffer N, Clark L, Bhadrakom C, Siriwasin W, Chearskul S, et al. Impact of HIV on families of HIV-infected women who have recently given birth, Bangkok, Thailand. Journal of acquired immune deficiency syndromes and human retrovirology : official publication of the International Retrovirology Association. 1998;18(1):54-63.

14. Yang Y, Lewis FM, Wojnar D. Life Changes inWomen InfectedWith HIV by Their Husbands: An Interpretive Phenomenological Study. Journal of the Association of Nueses in AIDS Care. 2015;26(5):58094.

15. Rodney P, Ceesay KF, Wilson ON. Addressing the Impact of HIV/AIDS on Women and Children in SubSaharan Africa: PEPFAR, the U.S. Strategy. Africa Today. 2010;57(1):64-76.

16. Mugambi J. The impact of HIV/AIDS on Kenyan rural women and the role of counseling. International Social Work. 2006;49(1):87-96.

17. Falleiro PS, Noronha MS. Economic Impact of HIV/AIDS on Women. Journal of Health Management. 2012;14(4):495-512.

18. Nielsen L. Classification of Countries Based on Their Level of Development : How It Is Done and How It Could Be Dones. USA: International Monetary Fund; 2011.

19. UNCTAD. The Least Developed Countries Report 2012. USA: United Nations Conference on Trade and Development; 2012.

20. UNDP. Human Development Indices and Indicators. New York, USA: The United Nations Delopment Program; 2018.

21. Songwathana P. Women and AIDS caregiving: women's work? Health Care Women Int. 2001;22(3):263-79.

22. Willie TC, Overstreet NM, Peasant C, Kershaw T, Sikkema KJ, Hansen NB. Anxiety and Depressive Symptoms Among People Living with HIV and Childhood Sexual Abuse: The Role of Shame and Posttraumatic Growth. AIDS Behav. 2016;20:1609-20. 
23. Ashaba S, Kaida A, Coleman JN, Burns BF, Dunkley E, Kasey ON, et al. Psychosocial challenges facing women living with HIV during the perinatal period in rural Uganda. PLoS One. 2017;12(5).

24. Chi BK, Hanh NT, Rasch V, Gammeltoft T. Induced abortion among HIV-positive women in Northern Vietnam: exploring reproductive dilemmas. Culture, Health \& Sexuality. 2010;12:S41-54.

25. Paxton S, Gonzales G, Uppakaew K, Abraham KK, Okta S, Green C, et al. AIDS-related discrimination in Asia. AIDS Care. 2005;17(4):413-24.

26. Logie C, Gadalla TM. Meta-analysis of health and demographic correlates of stigma towards people living with HIV. AIDS Care. 2009;21(6):742-53.

27. Overstreet NM, Earnshaw VA, Kalichman SC, Quinn DM. Internalized stigma and HIV status disclosure among HIV-positive black men who have sex with men. AIDS Care. 2013;25(4):466-71.

28. Smit PJ, Brady M, Carter M, Fernandes R, Lamore L, Meulbroek M, et al. HIV-related stigma within communities of gay men: a literature review. AIDS Care. 2012;24(4):405-12.

29. Joana Briggs Institute. Critical Appraisal Tools Australia: Joana Briggs Institute; 2017 [Available from: http://joannabriggs.org/research/critical-appraisal-tools.html.

30. Popay J, Roberts H, Sowden A, Petticrew M, Arai L, Rodgers M, et al. Guidance on the Conduct of Narrative Synthesis in Systematic Reviews: A Product from the ESRC Methods Programme. Lancaster: Narrative Synthesis in Systematic Reviews; 2006.

31. Husk K, Lovell R, Cooper C, Stahl-Timmins W, Garside R. Participation in environmental enhancement and conservation activities for health and well-being in adults: a review of quantitative and qualitative evidence. Cochrane Database of Systematic Reviews. 2016(5):CD010351.

32. Thomas J, Harden A. Methods for the thematic synthesis of qualitative research in systematic reviews. BMC Medical Research Methodology. 2008;8(45):1-10.

33. Brittain K, Mellins CA, Phillips T, Zerbe A, Abrams EJ, Myer L, et al. Social Support, Stigma and Antenatal Depression Among HIV-Infected Pregnant Women in South Africa. AIDS Behav. 2017;21:27482.

34. Withell B. A study of the experiences of women living with HIV/AIDS in Uganda. International Journal of Palliative Nursing, 2000, Vol 6, No 5. 2000;6(5):234-44.

35. Yator O, Mathai M, Vander Stoep A, Rao D, Kumar M. Risk factors for postpartum depression in women living with HIV attending prevention of mother-to-child transmission clinic at Kenyatta National Hospital, Nairobi. AIDS Care. 2016;28(7):884-9. 
36. Bauman LJ, Foster G, Silver EJ, Berman R, Gamble I, Muchaneta L. Children caring for their ill parents with HIV/AIDS. Vulnerable Children and Youth Studies. 2006;1(1):56-70.

37. Dane B. Disclosure: The voices of Thai women living with HIV/AIDS. International Social Work. 2002;45(2):185-204.

38. de Souza R. Women living with HIV: Stories of powerlessness and agency. Women's Studies International Forum. 2010;33(3):244-52.

39. Nguyen TA, Oosterhoff P, Ngoc YP, Wright P, Hardon A. Self-help groups can improve utilization of postnatal care by HIV-infected mothers. JANAC: Journal of the Association of Nurses in AIDS Care. 2009;20(2):141-52.

40. Subramaniyan A, Sarkar S, Roy G, Lakshminarayanan S. Experiences of HIV Positive Mothers From Rural South India during Intra-Natal Period. Journal of clinical and diagnostic research : JCDR. 2013;7(10):2203-6.

41. Bennetts A, Shaffer N, Manopaiboon C, Chaiyakul P, Siriwasin W, Mock P, et al. Determinants of depression and HIV-related worry among HIV-positive women who have recently given birth, Bangkok, Thailand. Social science \& medicine (1982). 1999;49(6):737-49.

42. Ruffell S. Stigma kills! The psychological effects of emotional abuse and discrimination towards a patient with HIV in Uganda. BMJ Case Rep. 2017;1(1):1-8.

43. Chi BK, Hanh NTT, Rasch V, Gammeltoft T. Induced abortion among HIV-positive women in Northern Vietnam: Exploring reproductive dilemmas. Culture, Health \& Sexuality. 2010;12(Suppl 1):S41-S54.

44. The United Nations. The Impact of AIDS. New York, USA: United Nations Department of Economic and Social Affairs/Population Division; 2004.

45. Harrison A, Short SE, Tuoane-Nkhasi M. Re-focusing the Gender Lens: Caregiving Women, Family Roles and HIV/AIDS Vulnerability in Lesotho. AIDS Behav. 2014;18(3):595-604.

46. McGrath JW, Ankrah EM, Schumann DA, Nkumbi S, Lubega M. AIDS and the urban family: Its impact in Kampala, Uganda. AIDS Care. 1993;5(1):55-70.

47. Mugweni E, Pearson S, Omar M. Traditional gender roles, forced sex and HIV in Zimbabwean marriages. Culture, Health \& Sexuality. 2012;14(5):577-90.

48. Patel SN, Wingood GM, Kosambiya JK, McCarty F, Windle M, Yount K, et al. Individual and interpersonal characteristics that influence male-dominated sexual decision-making and inconsistent condom use among married HIV serodiscordant couples in Gujarat, India: results from the positive Jeevan Saathi study. AIDS Behav. 2014;18(10):1970-80. 
49. Yang Y, Lewis FM, Wojnar D. Culturally Embedded Risk Factors for Cambodian Husband-Wife HIV Transmission: From Women's Point of View. Journal of Nursing Scholarship. 2016;48(2):154-62.

50. Deininger K, Crommelynck A, Kempaka G. Impact of AIDS on Family Composition, Welfare, and Investment: Evidence from Uganda. Rev Dev Econ. 2005;9:303-24.

51. Fauk NK, Mwakinyali SE, Putra S, Mwanri L. The socio-economic impacts of AIDS on families caring for AIDS-orphaned children in Mbeya rural district, Tanzania. International Journal of Human Rights in Healthcare. 2017;10(2):132-45.

52. Mahal A, Canning D, Odumosu K, P. O. Assessing the economic impact of HIV/AIDS on Nigerian households: a propensity score matching approach. AIDS. 2008 Suppl 1:S95-101.

53. Zhang X, Zhang Y, Aleong T, Baker T, Fuller-Thomson E. Factors associated with the Household Income of Persons Living with HIV/AIDS in China. Glob J Health Sci. 2012;4:108-16.

54. Guo Y, Li X, Sherr L. The impact of HIV/AIDS on children's educational outcome: A critical review of global literature. AIDS Care. 2012;24:993-1012.

55. Pufall LP, Nyamukapa C, Eaton JW, Campbell C, Skovdal M, Munyati S, et al. The impact of HIV on children's education in eastern Zimbabwe. AIDS Care. 2014;26:1136-43.

56. New York State AIDS Advisory Council. Women in Peril HIV \& AIDS: The Rising Toll on Women of Color. New York, USA: New York State AIDS Advisory Council; 2005.

57. Rodney P, Ndjakani Y, Ceesay FK, Wilson NO. Addressing the Impact of HIV/AIDS on Women and Children in Sub-Saharan Africa: PEPFAR, the U.S. Strategy. Afr Today. 2011;57:66-91.

58. Chippindale S, French L. HIV counselling and the psychosocial management of patients with HIV or AIDS. BMJ Case Rep. 2001;322(7301):1533-5.

59. Schweitzer A-M, Mizwa MB, Ross M. Psychosocial Aspects of HIV/AIDS: Adults. In: Schweitzer A-M, Mizwa MB, Ross M, editors. HIV Curriculum for the Health Professional. Texas, USA: Baylor College of Medicine; 2010.

60. Wilson MG, Husbands W, Makoroka L, Rueda S, Greenspan NR, Eady A, et al. Counselling, Case Management and Health Promotion for People Living with HIV/AIDS: An Overview of Systematic Reviews. AIDS Behav. 2013;17(5):1612-25.

61. Li L, Wu S, Wu Z, Sun S, Cui H, Jia M. Understanding Family Support for People Living with HIV/AIDS in Yunnan, China. AIDS Behav. 2006;10(5):509-17.

62. Stynes R, Lipp J, Minichiello V. HIV and AIDS and "family" counselling: A systems and developmental perspective. Counselling Psychology Quarterly. 1996;9(2):131-41. 
63. Yu YJ, Li X, Qiao S, Zhou Y. Family Relations in the Context of HIV/AIDS in Southwest China. AIDS Care. 2016;28(10):1261-8.

64. Lalonde B, Uldall KK, J. HG, Panter AT, Zalumas J, Wolfe LR, et al. Impact of HIV/AIDS education on health care provider practice: results from nine grantees of the Special Projects of National Significance Program. Eval Health Prof. 2002;25(3):302-20.

65. Henderson H, German VF, Panter AT, Huba GJ, Rohweder C, Zalumas J, et al. Systems change resulting from HIV/AIDS education and training. A cross-cutting evaluation of nine innovative projects. Eval Health Prof. 1999;22(4):405-26.

66. Fox MP, Rosen S. A new cascade of HIV care for the era of "treat all". Plos Med. 2017;14:4-11.

67. WHO. Consolidated Guidelines on the Use of Antiretroviral Drugs for Treating and Preventing HIV Infection: Recomendation for a Public Health Approach. Geneva, Switzerland: World Health Organization; 2016.

\section{Tables}

Due to technical limitations, Tables $1 \& 2$ are only available as downloads in the supplemental file section.

\section{Figures}




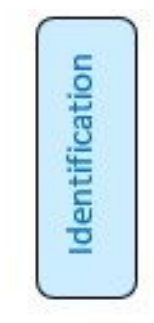

Records identified through database searching ( $n=3,316$ )

-Medline $=1,259 ; \cdot{ }^{-S}$ Copus $=1,433 ; \cdot{ }^{*} \mathrm{CINAHL}=$

$53 ; \cdot-$ PsylNFO $=53 ; \bullet$ Emcare $=102 *$ ProQuest $=$ 416
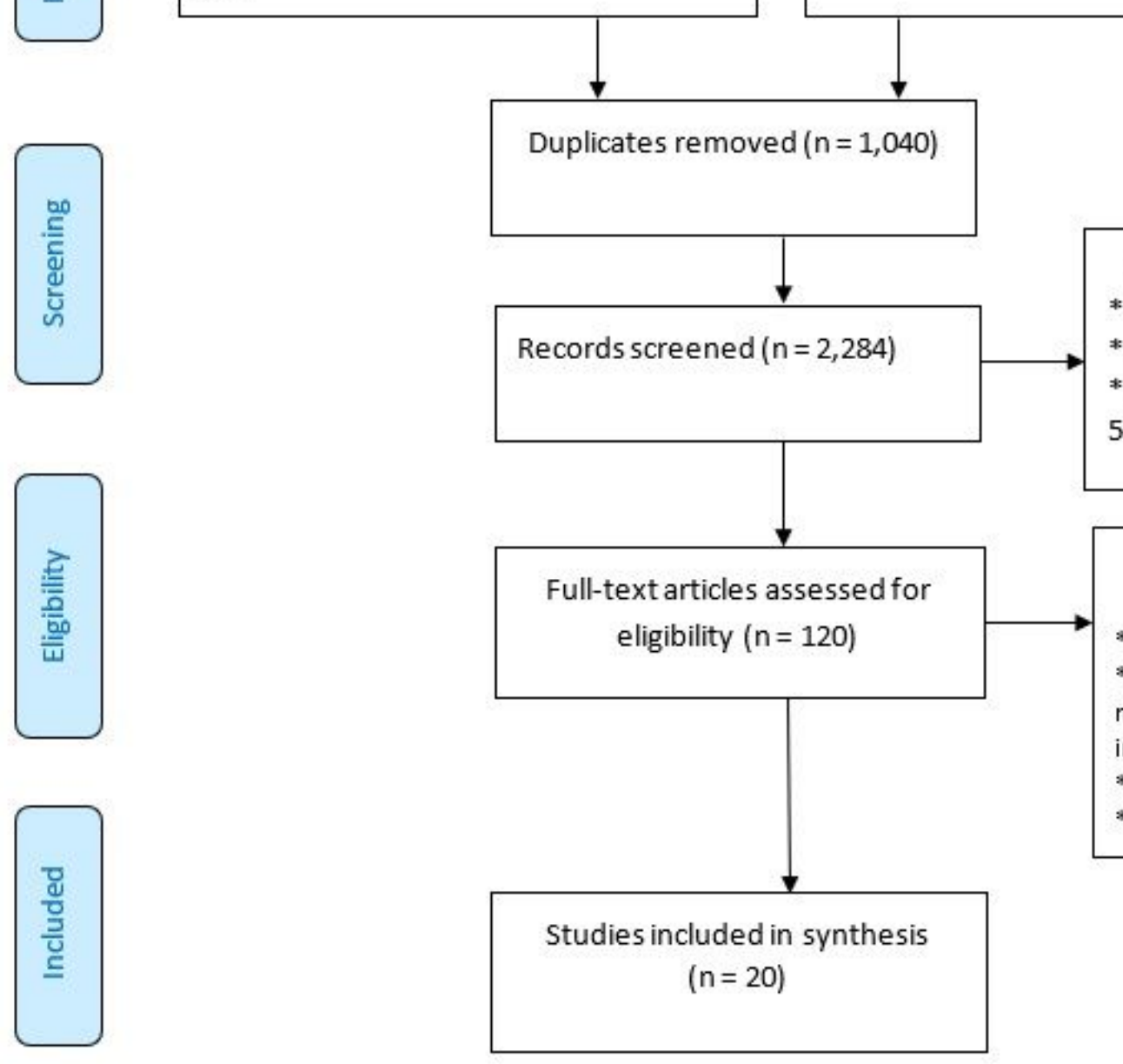


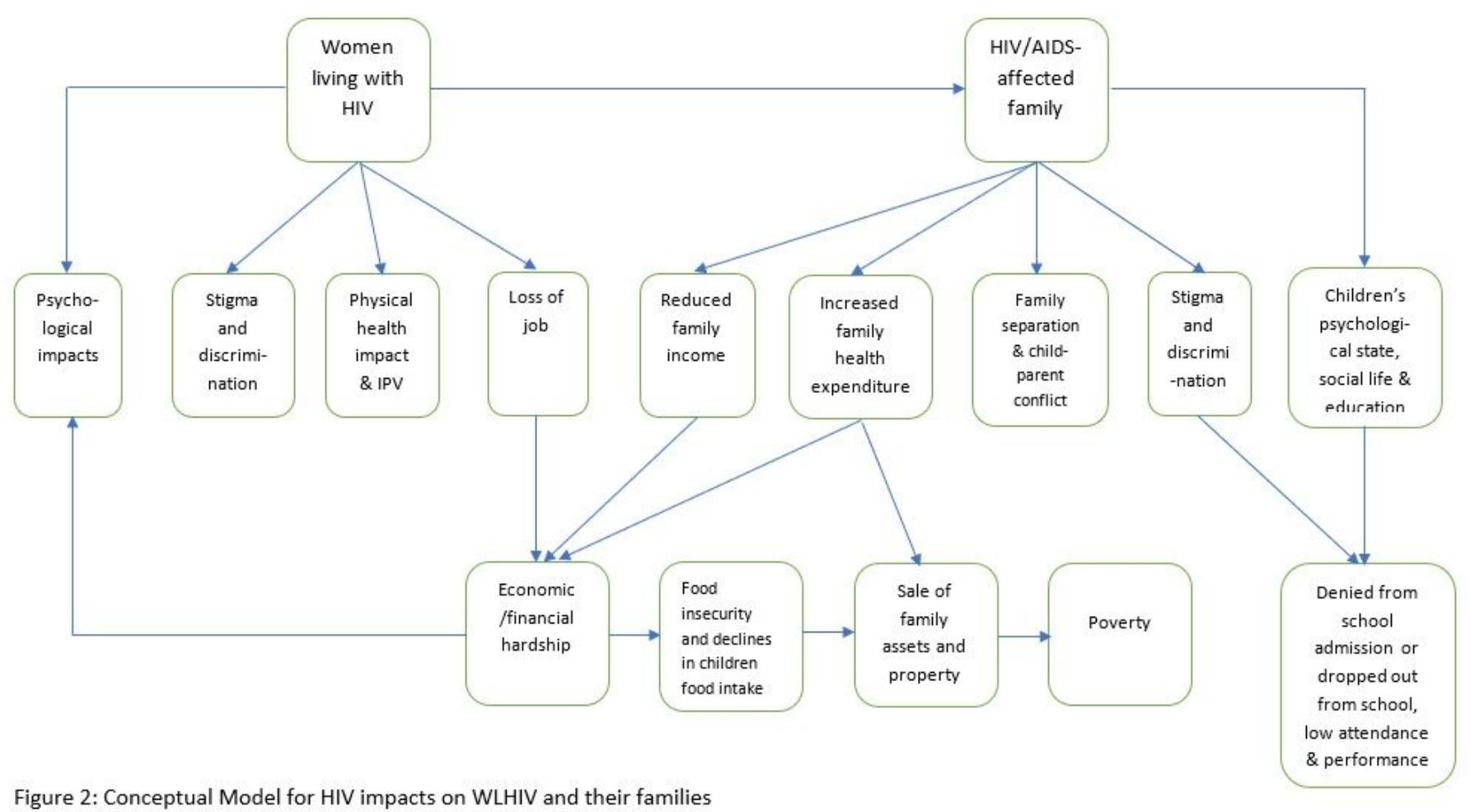

Figure 2

Conceptual Model for HIV impacts on WLHIV and their families

\section{Supplementary Files}

This is a list of supplementary files associated with this preprint. Click to download.

- AppendixA.pdf

- Tables.pdf 